\title{
Structural and Antibacterial Activity of Copper Oxide Nano Particles
}

\author{
A.Pricilla Jeyakumari ${ }^{1}$, M.Ramakrishnan ${ }^{1}$, Y.Nithyanandhi ${ }^{1}$, S.Renuka ${ }^{2}$ \\ ${ }^{I}$ Thiruvalluvar Government Arts College, Rasipuram, Tamil Nadu, India \\ ${ }^{2}$ Gnanamani Engineering College, Paachal, Namakkal,Tamil Nadu, India.
}

\begin{abstract}
Nano particles of metal oxides are manufactured in the large scale because of their industrial applications. Copper Oxide is an important p-type semiconductor, has drawn increasing attention in the application of gas sensors because of low cost, excellent reactivity, high stability and non-toxicity, and also the secondary architectures composed of nanostructured building blocks have attracted significant interest in material synthesis and device fabrications. In the present investigation pure and $\mathrm{Ni}, \mathrm{Cd}$ doped CuOnano particles have been prepared by co-precipitation method. The crystalline natures of the sample were also confirmed by X-ray diffraction pattern. The crystalline size of the pure and Cd,Ni doped nano particle were determined as $13 \mathrm{~nm}, 12 \mathrm{~nm}$ and $14 \mathrm{~nm}$ respectively. FT-IR spectra identify the functional group present in the molecular structure. There is a shift in the lower frequency region confirmed the presence of the dopants $(\mathrm{Ni}, \mathrm{Cd})$. The surface morphology of the prepared materials were also analysed by FE-SEM. It reveals the polycrystalline porous morphology with a nano flower structure. The small crystallites agglomerated to form nanoflowers and nano sheets. The energy gap value for pure and doped $(\mathrm{Ni}, \mathrm{Cd}) \mathrm{CuO}$ were also determined. Anti-bacterial studies shows that the zone of inhibition is high for the $\mathrm{CuO}$ and doped (Ni,Cd) CuOnano particle. $\mathrm{CuO}$ nanoparticle exhibited strong antibacterial activity against bacterial species.
\end{abstract}

Keywords: Antibacterial activity, Co-precipitation, Copper Oxide, FT-IR, Nanoflower, SEM, XRD.

\section{Introduction}

Nano materials have attracted much attention in recent years because of their outstanding properties and potential applications, exhibited neither by small molecular system nor by larger particulate matter[1]. Nano particles of metal oxides are already manufactured in large scale because of their industrial applications.Nanocopper oxide $(\mathrm{CuO})$ is a well-known $\mathrm{p}$ - type narrow band gap semiconductor with lower band gap $1.2 \mathrm{eV}$ ( at room temperature ) is mainly used in many application such as catalysis, photo-catalysis, humidity, gas sensors, magnetic storage media, solar energy transformation, electronics and super capacitor. Nanoparticles of copper oxide have potential to replace noble catalysts for carbon monoxide oxidation. Nano fluids of $\mathrm{CuO}$ nanoparticles have excellent thermal conductivity suitable for their applications as heat transfer fluids in machine tools.[2] Beit like $\mathrm{CuO}$ nanoparticles exhibit an enhanced sensing performance towards formaldehyde and Ethanol vapours with rapid response and high sensitivity. $\mathrm{CuO}$ has complex magnetic phases; forms the basis for several high Tcsuperconductors and material with giant magneto resistance. Recently, $\mathrm{CuO}$,as an important $\mathrm{p}$-type semiconductor, has drawn increasing attention in the application of gas sensors because of low cost, excellent reactivity, high stability and nontoxicity, and also the secondary architectures composed of nanostructured building blocks have attracted significant interest in material synthesis and device fabrications. [3,4] This is because nanostructured semiconductors display wideapplications due to the strong relationship between their geometry and their function.It is generally agreed that properties of Cuo may be tuned or improved by developing materials with well-controlled characteristics such as high crystallinity, uniform size, shape and large surface area. Motivated by the application $\mathrm{CuO}$ nanoparticles were prepared by co-precipitation method. In the present work the prepared pure \& $\mathrm{Cd}, \mathrm{Ni}$ doped CuOnanomaterials were characterized by powder X-Ray diffraction method and FT-IR spectrum analysis.[5] The morphology of the nanomaterial were determined by scanning electron microscopy (FESEM).The Antibacterial activity of the pure and $\mathrm{Ni}$ doped $\mathrm{CuO}$ were also studied and presented.[6] 


\section{Experimental}

2.1 Synthesis of pure copper oxide and $\mathrm{Cd}$, $\mathrm{Ni}$ doped copper oxide

$0.05 \mathrm{M}$ of copper(II) chloride di-hydrate $\left[\mathrm{Cucl}_{2} .2 \mathrm{H}_{2} \mathrm{O}\right]$ and $0.5 \mathrm{mM}$ of poly ethylene glycol were dissolved in $150 \mathrm{ml}$ of distilled water and stirred for 15 mints [solution A].Then $150 \mathrm{ml}$ of $0.6 \mathrm{M}$ of sodium hydroxide solution (solution B) was added drop wise into the above solution under constant stirring. Then the obtained blue precipitate of copper hydroxide was stirred and heated at $50^{\circ} \mathrm{C}$ for 1 hour to get black precipitate of $\mathrm{CuO}$. The black precipitate thus formed was centrifuged and washed with distilled water, absolute ethanol and acetone and then kept in the muffle furnace at $100^{\circ} \mathrm{C}$ for one hour a black solid were obtained, and then it grained by milling process to obtainedCuOnanopalticles.[3] $0.002 \mathrm{M}$ cadmium sulphate were added with the solution $\mathrm{A}$ and the same procedure was followed to get $\mathrm{Cd}$ doped $\mathrm{CuO}$ nanoparticles. Similarly $0.002 \mathrm{M}$ Nickel Chloride was added to the solution $\mathrm{A}$ to get $\mathrm{Ni}$ doped $\mathrm{CuO}$ nanoparticles.

\section{Characterization Techniques Structural Characterization}

\subsection{Powder X-Ray Diffraction Pattern}

The x-ray diffraction analysis of pure $\mathrm{CuO}$ and $\mathrm{Cd}, \mathrm{Ni}$ doped $\mathrm{CuO}$ nanoparticle were carried to identify the crystal structure as shown infig (3.1,3.2.3.3). All diffraction peaks are index with the corresponding planes of $\mathrm{CuO}, \mathrm{Cd}-\mathrm{CuO}$ and $\mathrm{Ni}-\mathrm{CuO}$. The peaks 35.48, 53.1, 61.5, 66.04 which match well with the plane (-1 111$),(-20$ 2),(0 2 0),(2 0 2 2),(0 2 2 2). andNi-CuO peaks 35.3, 39.17, 49.7, 53.2, 62.2, 65.1, 67.5, 66.04 which match well

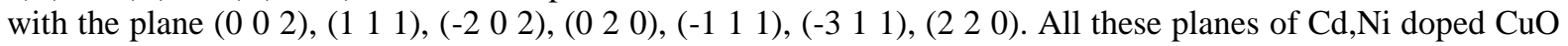
crystal structure are very close to the JCPDS9(05-0661) values of CuO. The X-ray diffraction well agree with the monoclinic phase of copper oxide.[7,8]

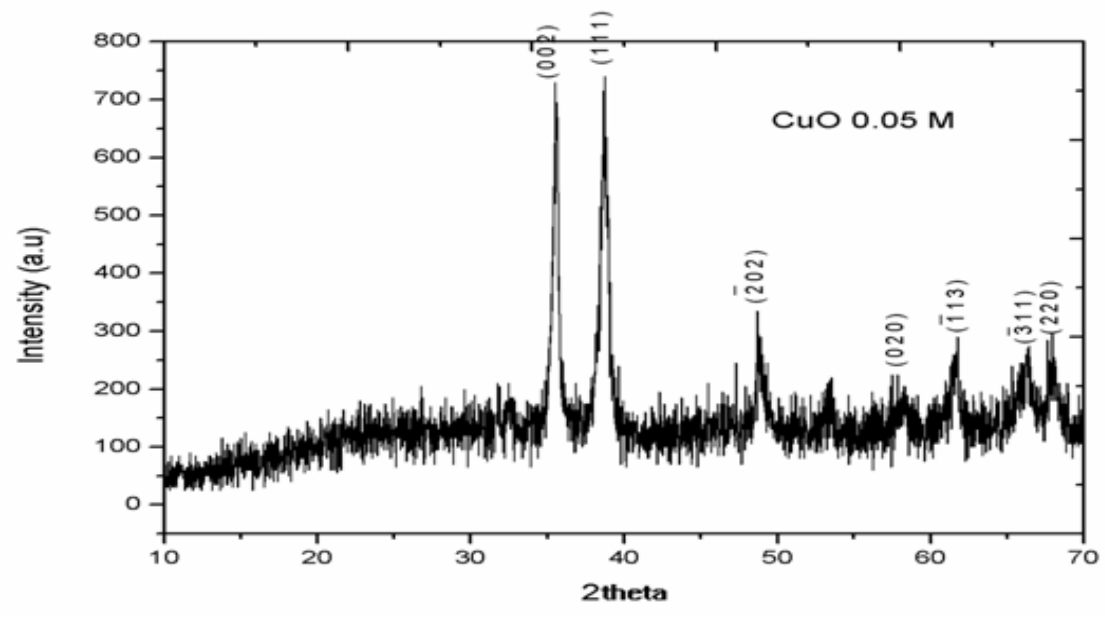

Fig 3.1 XRD Pattern of Copper Oxide



Fig 3.2 XRD Pattern of ${ }^{2 \theta} d$ doped $\mathrm{CuO}$ 


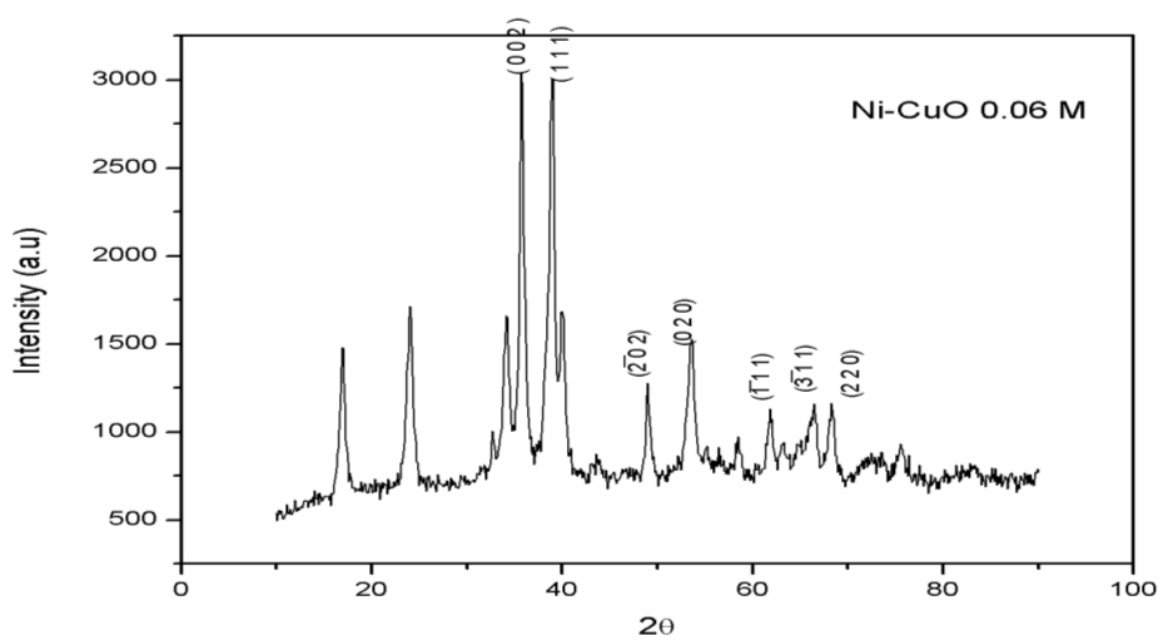

Fig 3.3 XRD Pattern of Ni doped Copper

No other diffraction peaks arising from metallic $\mathrm{Cu}$ or $\mathrm{Cu}_{2} \mathrm{O}$ present in the XRD pattern were observed. The crystal structure of the samples were examined by X-ray diffraction, with $\mathrm{Cu} K \alpha(\lambda=1.54056)$ in $2 \theta$ range. The crystallite sizes of the particles were calculated by using Sherrer's equation.

$$
\mathbf{D}=\mathbf{k} \square / \square \cos \square
$$

Where, $\mathrm{D}$ is the crystallite size of the particles , $\mathrm{K}$ is a shape factor $\quad(\mathrm{K}=0.9$ in this work $), \lambda$ is the wavelength of the incident $\mathrm{X}-\operatorname{ray}(1.5405 \AA, \mathrm{CuK} \alpha), \theta$ is the diffraction angle and $\beta$ is the full width half maximum. The calculated particle size for pure $\mathrm{CuO}$ is $13 \mathrm{~nm}$ and for $\mathrm{Cd}-\mathrm{CuO}$ is 12 and $\mathrm{Ni}-\mathrm{CuO}$ is $14 \mathrm{~nm}$. The addition of impurities like $\mathrm{Cd}$, $\mathrm{Ni}$ causes a slight modification in the size of the nanoparticles.

\subsection{FT-IR Spectroscopy}

The FTIR spectrum of $\mathrm{CuO}$ shows the three strong peaks at $418.58 \mathrm{~cm}^{-1}, 498.21 \mathrm{~cm}^{-1}$, and $611.31 \mathrm{~cm}^{-1}$ and $\mathrm{Cd}$,Ni doped $\mathrm{CuO}$ shows at $426.5 \mathrm{~cm}^{-1}, 420.02 \mathrm{~cm}^{-1}$ and $601.4 \mathrm{~cm}^{-1}$ are associated with the $\mathrm{Cu}-\mathrm{O}$ vibrations of mono clinic Copper oxide.The bandslocated at above $498.21 \mathrm{~cm}^{-1}$ and $490.54 \mathrm{~cm}^{-1}$ are due to the $\mathrm{Cu}-\mathrm{O}$ stretching along the direction for both $\mathrm{Cd}, \mathrm{Ni}-\mathrm{CuO}$ similarly that at about $611.31 \mathrm{~cm}^{-1}, 615.84 \mathrm{~cm}^{-1}$ is associated with $\mathrm{Cu}-\mathrm{O}$ stretching.The peaks for $\mathrm{Cd}$,Ni-CuOcentred at $418.58 \mathrm{~cm}^{-1}, 420.02 \mathrm{~cm}^{-1}$ and $498.21 \mathrm{~cm}^{-1}, 490.54 \mathrm{~cm}^{-1}$ show blue shift and the peak $611.31 \mathrm{~cm}^{-1}, 615.84 \mathrm{~cm}^{-1}$ show red shift compared with the reported values $(429,502$ and $591 \mathrm{~cm}^{-1}$ respectively).The broad peaks at about $3401.85 \mathrm{~cm}^{-1}, 3574.69 \mathrm{~cm}^{-1}$ and $3392.4 \mathrm{~cm}^{-1}, 3329.89 \mathrm{~cm}^{-1}$ are related to the $\mathrm{O}-\mathrm{H}$ stretching ofhydroxyl group absorbed on the surface of the sample, which is further confirmed by the band at about $1629.9 \mathrm{~cm}^{-1}, 1709.01 \mathrm{~cm}^{-1}$. The O-H peak at $3401.85 \mathrm{~cm}^{-1}, 3329.89 \mathrm{~cm}^{-1}$ associated with defectsand free carrier concentration [8,9].The vibrational frequency of pure $\mathrm{CuO}$ at $865 \mathrm{~cm}^{-1}$ is shifted to $993.85 \mathrm{~cm}^{-1}$ in $\mathrm{Ni}$ doped $\mathrm{CuO}$ confirms the presence of $\mathrm{Ni}-\mathrm{O}$ stretching.The corresponding graphs are shown in fig $[3.4,3.5 .3 .6]$.



Fig 3.4FT-IR spectrum of pure copper oxide. 


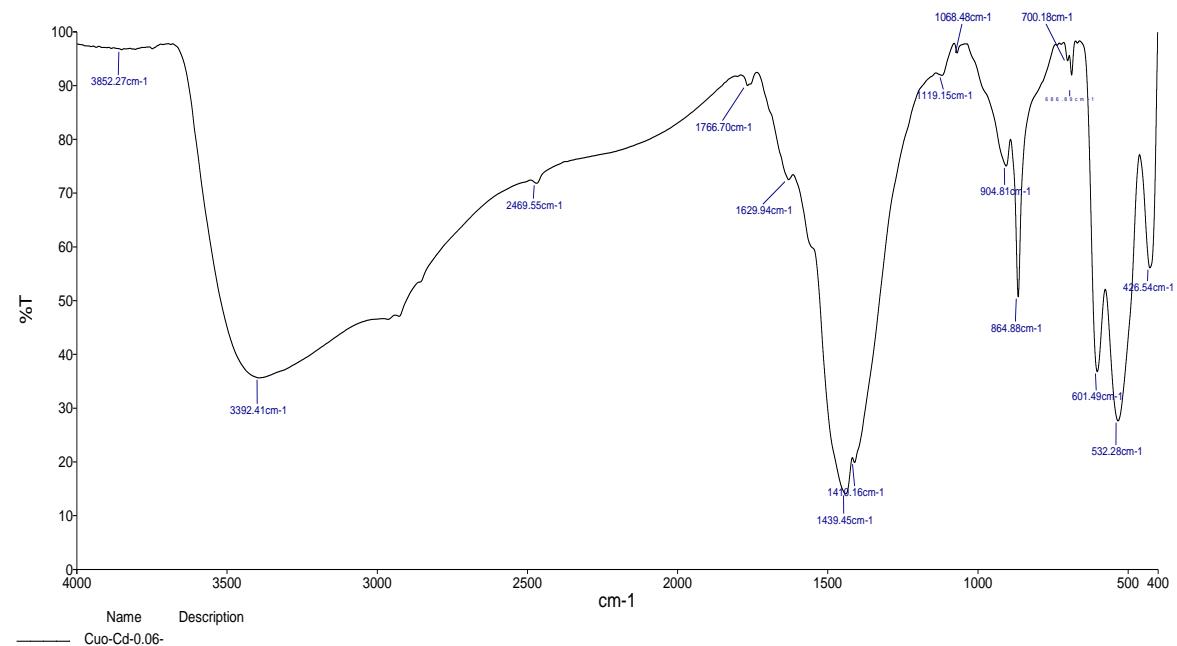

Fig 3.5 FT-IR spectrum of Cd doped Copper Oxide.

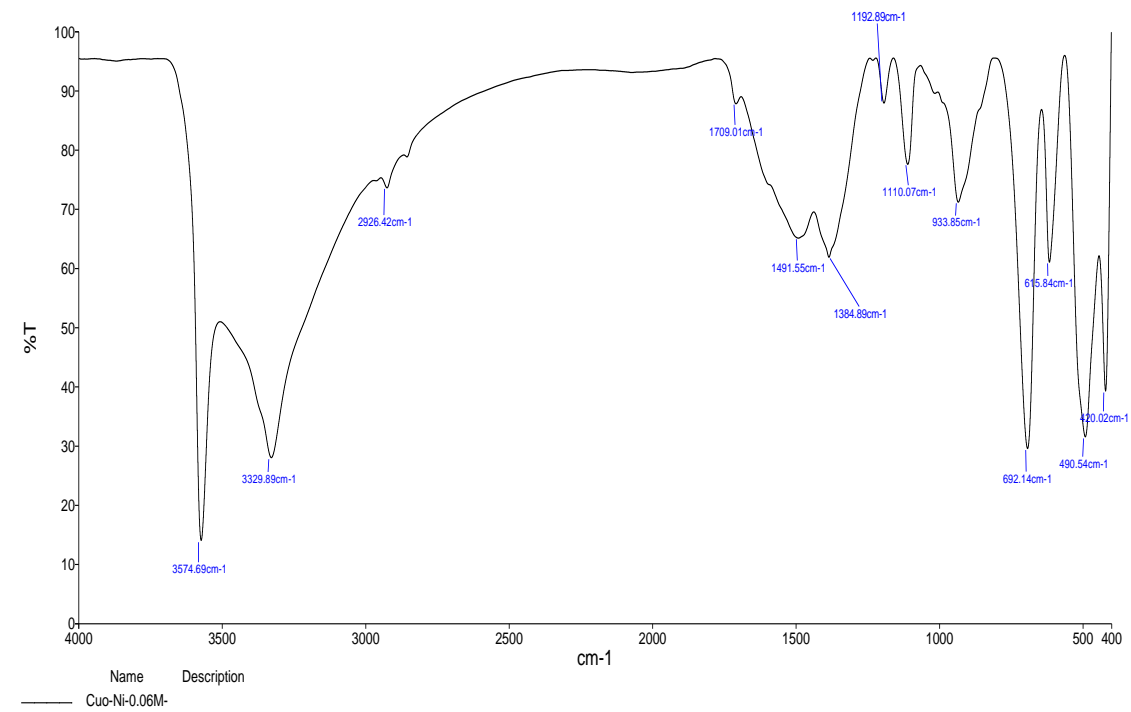

Fig 3.6 FT-IR spectrum of Ni doped Copper Oxide.

\subsection{Surface Morpholody}

\subsubsection{Scanning Electron Microscope}

Figure[3.7] shows pure $\mathrm{CuO}$ scanning electron microscopy (SEM) micrograph of prepared nano particle scanned by $20 \mathrm{KV}$ electron beam at different X20,000,X30,000 and X10,000,X55,000 magnification. The SEM image reveals the polycrystalline, porous morphology with the nano fused surface. The small crystallites agglomerated to form nano cluster ellipticalnano particle and nano sheets.Fig[3.8] shows the scanning electron microscopy (SEM) micrograph of prepared Cd-doped CuOnano particle scanned by $20 \mathrm{KV}$ electron beam atX20,000,X30,000 and X10,000,X55,000 different magnification. The SEM image reveals the crystalline, porous[11,12] morphology with the inter-connected grain presented on the nano surface. The small crystallites agglomerated to form nanoflower with stem, rice like structure nano particle may provide novel platform for photovoltaic sensor and other device applications.[10,11] 

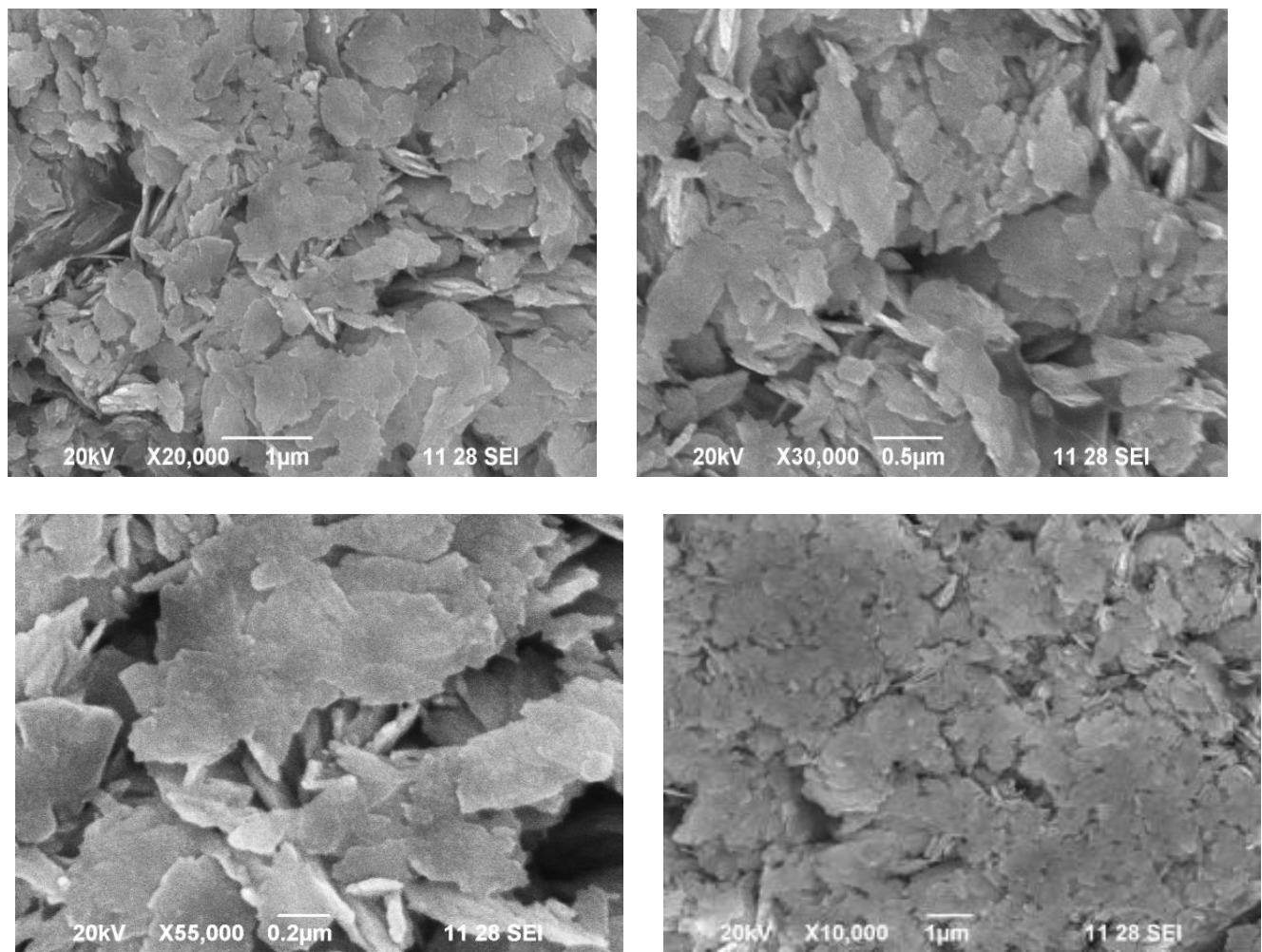

Fig 3.7 SEM image of pure $\mathrm{CuO}$


Fig 3.8SEM image of Cd doped Copper Oxide 


\section{6antibacterial Activity}

Many antibacterial studies were made using different nanoparticles. The reason for anti-bacterial studies is due to the presence of reactive oxygen species generated by different nanoparticles[12-16 ]. Chemical interaction between hydrogen peroxide and membrane proteins or between the chemical produced in the presence of $\mathrm{CuO}, \mathrm{Ni} \mathrm{CuOnano}$ particles and the outer bilayer hydrogen peroxide to medium. In fig 3.12 we clearly see the antibacterial activityof the bacteria is completely destroyed and anti-bacterial activity still active. The result revealed that the antibacterial activity are sensitive to the test samples. The Antibacterial strains is summarized in table shows that the CuOshowed good antibacterial activity against the various bacterium like Staphylococcusaureus (Gram +ve), Salmonella typhi (Gram -ve), Bacillus sutilis, Escherichia coli their interaction with $\mathrm{CuO}$ are shown in fig (3.12) and also zone of inhibition is given in table.1.As the diameter of the zone of inhibition is high, we can conclude that $\mathrm{CuO}$ is very effective antibacterial agent.
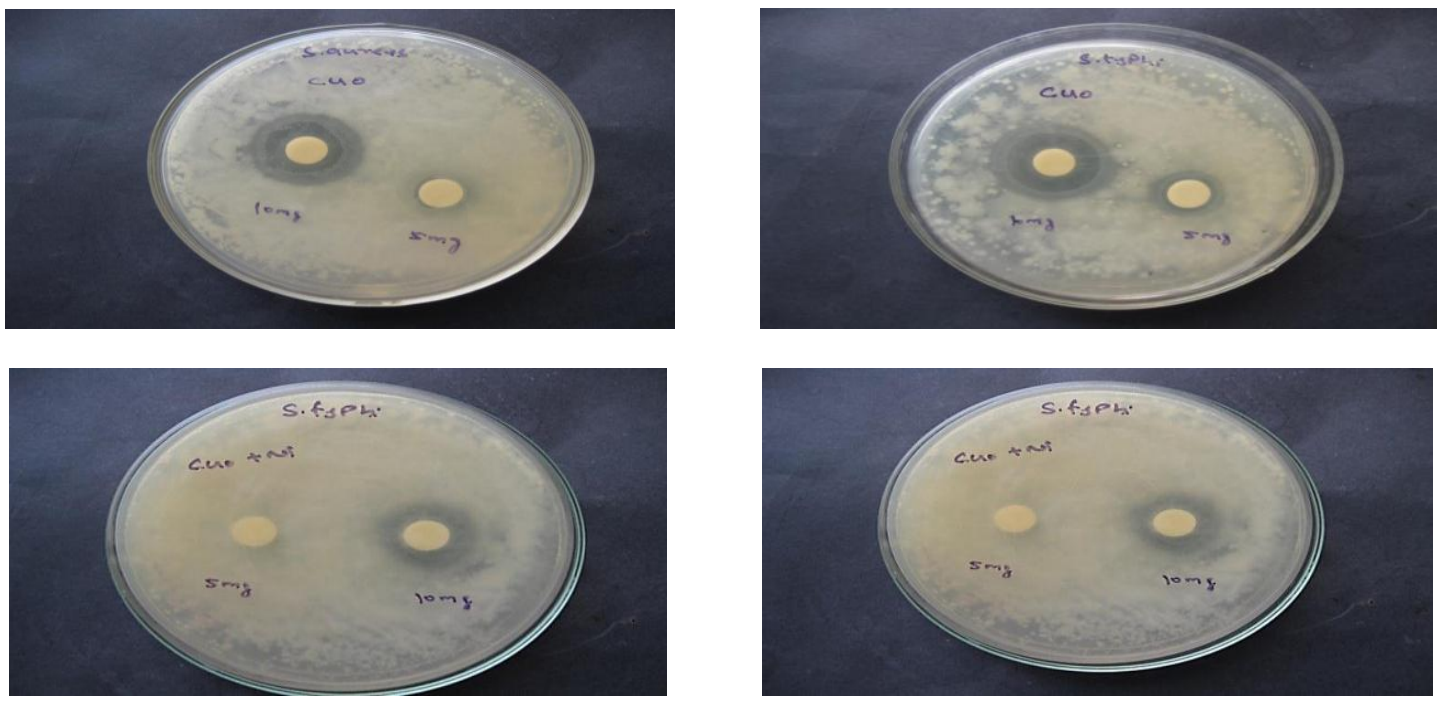

Fig 3.12 Antibacterial activity of Copper Oxide on Staphylococusaureus, salmonella typi

Table1 Zone of inhibition of $\mathrm{CuO}$ and $\mathrm{Ni}$ doped copper oxide

\begin{tabular}{|l|l|l|l|l|}
\hline Zone of inhibition in mm & Copper Oxide & \multicolumn{2}{l|}{ Ni-Copper Oxide } \\
\hline Name of the sample & $5 \mathrm{mg}$ & $10 \mathrm{mg}$ & $5 \mathrm{mg}$ & $10 \mathrm{mg}$ \\
\hline Name of the microorganisms & $11 \mathrm{~mm}$ & $26 \mathrm{~mm}$ & $11 \mathrm{~mm}$ & $26 \mathrm{~mm}$ \\
\hline Staphylococcus aureus & $10 \mathrm{~mm}$ & $25 \mathrm{~mm}$ & $11 \mathrm{~mm}$ & $25 \mathrm{~mm}$ \\
\hline Salmonella typhi &
\end{tabular}

\section{Conclusion}

$\mathrm{CuO}$ nanomaterial was synthesized by co-precipitation method at room temperature. The material investigated here are the oxide of earth-abundant material. The powder X-ray diffraction pattern of the synthesized $\mathrm{CuO}$ confirm that the material is a nanomaterial of the particle sizeCuO andCd, $\mathrm{Ni}$ dopedCuO are $12.6 \mathrm{~nm}$ and $11.8 \mathrm{~nm}, 14.17 \mathrm{~nm}$ respectively. The functional groups in the Copper oxide and $\mathrm{Cd}, \mathrm{Ni}$ doped copper oxide nanomaterial has been confirmed by FT-IR spectral analysis..Low cost production is the main advantage for any product to compete in the market and $\mathrm{CuOnano}$ structures being solution process able provide much potential to become the choice for cheap devices.The surface morphology of the samples were determined and structure confirmed by SEM.The CuOnano structure is of great importance because it enables fabrication of humidity sensor with improved performance at low cost, which may be breakthrough for the development of an efficient humidity sensor.

\section{References}

[1] Y.P. Sukhorukov, B.A. Gizhevskii, E.V. Mostovshchikova, A.Y.Yermakov, S.N.Thugushev, E.V.Kozlov,Nano crystalline copper oxide for selective solar energy absorbers,Tech.Phys.Lett.32(2006) 132-135.

[2] R.V.Kumar, R.Elgamiet, Y.Diamant, A.Gedaken, J.Norwig Sonochemical preparation and characterization of Nano crystalline copper oxide embedded in poly(vinyl alcohol) and its effect on crystal growth of copper oxide ,langmuir18 (2002) 1352-1359.

[3] J.HuangS.WangY.Zhao,X.Wang,S.Wang,S.Zhang,W.Huang,Synthesis and characterization of $\mathrm{CuO} / \mathrm{TiO}_{2}$ catalysts for low-temperature CO Oxidation, Catal,Commun,7 (2006) 1029-1034.

[4] A.Nezamzadeh-Ejhieh,Z.Salimi,Heteroeneousphotodegradation catalysis of o-phenylenediamine using $\mathrm{CuO} / \mathrm{X}$ zeolite, Appl.Catal. A:Gen. 390 (2010) 110-118. 
[5] S.WangH.Hu,LQian,X.Jia,J.WangY.Tang CTAB-Assisted synthesis and photocatalytic property of CuO hollow microspheres,J.Solid State Chem.182 (2009) 1088-1093.

[6] Y.Li,X.Y. Yang J.RookeG.V.Tendeloo,B.L, Su,Ultralong $\mathrm{Cu}(\mathrm{OH})_{2}$ and $\mathrm{CuO}$ Nanowire Bundles: PEG200-Directed crystal growth for enhanced photocatalytic performance J.performanceJ.Colloid interface Sci.348(2010) 303-312.

[7] Z.Zhang J.C Yu, A.W. Xu,Q, Li, K.W.KwongS.H,Yu, Peanut-shaped nanoribbon bundle Superstructures of malachite and copper oxide J.Cryst.Growth 266 (2004) 545-551.

[8] X.WenW.Zhang,S.Tang,Synthesis of $\mathrm{Cu}(\mathrm{OH})_{2}$ and CuOnanoribbonarrys on a copper surface Langmuir 19(2003) 5898-5903.

[9] J.P. Liu,X.THuany, Y.Y. Li, K.M. Sulieman X. He, F.L,Sun Hierarchical nanostructures of cupric oxide on a copper substrate: controllable morphology and wettabilityJ.Mater.chem. 16 (2006) 4427-4434.

[10] C.L.Carnes, J.Stipp,K.J. Klabunde ,Synthesis, characterization , and adsorption studies of nanocrystalline copper oxide and nickel oxide Langmuir 18 (2002) 1352-1359.

[11] G.Kliche,Z.V. Popovic, Far-infrared spectroscopic investigations on CuO,Phys.Rev.B 42 (1990) 10060-10066.

[12] K.Borgohain,S.Mahamuni, Formation of single - phase CuO quantum particles, J.Mater. Res. 17 (2002) 1220-1223.

[13] M.Weller, H.M.Schmidt,U. Koch, A.Fojtik,S.Baral,A.Henglein.W.Kunath,K. Weiss, E.Dieman,Photochemistry of colloidal semiconductors:onset of light absorption as a function of size of extremely small Cdsparticles, Chem.Phys. Lett.124 (1986) 557-560.

[14] A.Manna, T.Imae ,T.Yogo,K.Aoi, M.Okazaki ,Synthesis of gold nanoparticles ion Winsor II Type Microemulsion and their characteriztion, J.colloide Interface Sci. 256 (2002) 297-303.

[15] Q. Pan, K.Huang ,S.NiF.Yang, S.linD.He,Synthesis of sheaf-like CuO from aqueous solution and their application in lithium -ion batteries ,J.Alloy. Comp. 484(2009) 322-326.

[16] B.A. Gizhevskii , Y.P. Sukhorukov, A.S. Moskvin, N.N. Loshkareva, E.V.Mostovshchikova, A.E.Ermakov,E.A. Kozlov,M.A. Uimin, V.S. Gaviko,Anomolies in the optical properties of nanocrystalline copper oxides $\mathrm{CuO}$ and $\mathrm{Cu}_{2} \mathrm{O}$ near the Fundamental absorption edge, J. Exp.Theor. Phys. 102 (2006) 297-302.

[17] M.Kenward, M.D. Whitmore, A Systematic Monte Carlo study of self -assembling amphiphiles in solution, J. Chem .Phys. 116(2002) 3455-3471.

[18] M.Weller, H.M. Schmidt,U.Koch, A.Fojtik,S.Baral,A.Henglein.W.Kunath,K. Weiss, E.Dieman,Photochemistry of colloidal semiconductors: onset of light absorption as a function of size of extremely small Cds particles, Chem.Phys. Lett.124 (1986) 557-560.

[19] G.Adamopoulos, A.Bashir, W.P. Gillin, Advanced functional materials 21(2011)525-531.

[20] A.Manna, T.Imae ,T.Yogo,K.Aoi, M.Okazaki ,Synthesis of gold nanoparticles ion Winsor II Type Microemulsion and their characteriztion, J.colloide Interface Sci. 256 (2002) 297-303.

[21] Cheng, M.-Y., Ye. -S., Chiu, T.-M., Pan, C.-j., Hwang, B.J.: Size effect of nickel oxide for lithium ion battery anode. J.Power Sour. 253, 27-34 (2014)

[22] Amirjani, A., Marashi, P., Fatmeshri, D.h.: Int Nano Lett. 4,108 (2014) 